\title{
Vertical Velocity and Buoyancy Characteristics of Coherent Echo Plumes in the Convective Boundary Layer, Detected by a Profiling Airborne Radar
}

\author{
Qun Miao And Bart Geerts \\ University of Wyoming, Laramie, Wyoming \\ Margaret LeMone \\ National Center for Atmospheric Research,* Boulder, Colorado
}

(Manuscript received 20 June 2005, in final form 8 November 2005)

\begin{abstract}
Aircraft and airborne millimeter-wave radar observations are used to interpret the dynamics of radar echoes and radar-inferred updrafts within the well-developed, weakly sheared continental convective boundary layer. Vertically pointing radar reflectivity and Doppler velocity data collected above and below the aircraft, flying along fixed tracks in the central Great Plains during the International $\mathrm{H}_{2} \mathrm{O}$ Project (IHOP_2002), are used to define echo plumes and updraft plumes, respectively. Updraft plumes are generally narrower than echo plumes, but both types of plumes have the dynamical properties of buoyant eddies, especially at low levels. This buoyancy is driven both by temperature excess and water vapor excess over the ambient air. Plumes that are better defined in terms of reflectivity or updraft strength tend to be more buoyant.
\end{abstract}

\section{Introduction}

The planetary boundary layer (PBL) links the earth surface to the free atmosphere; thus the PBL is important in the atmosphere's moisture and energy budget. The quality of especially warm-season quantitative precipitation forecasting is strongly affected by the ability of numerical weather prediction models to accurately parameterize fluxes across the PBL. Boundary layer processes also affect the presence and characteristics of shallow clouds, which have a pronounced impact on radiative transfer and global climate. Over land surfaces, solar heating and the resulting surface heat fluxes create convective eddies, that is, buoyancy-generated turbulent kinetic energy. These eddies transport moisture, heat, momentum, aerosol, and insects vertically, producing a mixed layer [the "convective" boundary

\footnotetext{
* The National Center for Atmospheric Research is sponsored by the National Science Foundation.
}

Corresponding author address: Bart Geerts, Department of Atmospheric Sciences, University of Wyoming, Laramie, WY 82071. E-mail: geerts@uwyo.edu layer (CBL)] characterized by a rather uniform potential temperature and mixing ratio at all levels (Stull 1988, p. 450).

Much effort has been devoted to the description of the continental CBL by means of both in situ and remote sensing observations. In situ observations have been made using tethered balloons (e.g., Readings et al. 1973), instrumented towers (e.g., LeMone 1973; Kaimal et al. 1976), and aircraft (e.g., Lenschow et al. 1980). Wind profilers have been used to describe the three-dimensional (3D) power spectrum of wind as a function of time and height (e.g., Angevine et al. 1993). Scanning or zenith-pointing backscatter lidar data provide highresolution velocity information in the CBL (e.g., Ferrare et al. 1991; Mayor et al. 2003). Ground-based scanning weather radar data have been used to describe the 2D and even 3D echo and velocity structure of cells or bands in the optically clear CBL (e.g., Wilson et al. 1994; Lohou et al. 1998a). This is only possible when there are enough scatterers (mostly insects).

In this study, airborne radar measurements of the $\mathrm{CBL}$ are combined with flight-level data to describe the thermodynamic and vertical velocity characteristics of coherent eddies observed under optically clear conditions. Coherent eddies are defined by either radar re- 
flectivity or radar-inferred vertical air motion in vertical cross sections along the flight track. Other investigators have demonstrated the utility of combining aircraft measurements with ground-based remote sensing data to characterize the CBL, using lidars (e.g., Crum et al. 1987) or radars (e.g., Reinking et al. 1981; Lohou et al. 1998a), although such a combination is hampered by poor time-space coincidence. Airborne nadir-pointing lidars have been used as well (e.g., Kiemle et al. 1995; White et al. 1999), but at flight levels well above the CBL. The radar used in this study documents the echo and vertical velocity structure of the CBL above and below the aircraft, at a vertical and along-track resolution of approximately $36 \mathrm{~m} \times 10 \mathrm{~m}$ (detailed below), and in close proximity to flight-level observations. These measurements were obtained in the mature CBL over the central Great Plains of North America in May-June 2002, as part of the International $\mathrm{H}_{2} \mathrm{O}$ Project (IHOP_2002; Weckwerth et al. 2004).

It has long been realized that radars can detect plumes of elevated reflectivity in the optically clear CBL. In fact, the reflectivity field is remarkably inhomogeneous in a region where conserved variables such as potential temperature and mixing ratio are rather well mixed. Radar scans at low elevation angles have been used to describe spatial structures of echoes, ranging from cells to parallel bands (Hardy and Ottersten 1969; Konrad 1970; Doviak and Berger 1980; Gossard 1990; Wilson et al. 1992; Xu and Gal-Chen 1993; Lohou et al. 1998b). In general, all of these studies have focused on the horizontal structure resulting from $3 \mathrm{D}$ circulations and dynamical forcing in the CBL, although the circulations and dynamical forcings are often not directly observed, especially not in the vertical dimension.

Many conditional sampling methods have been used to understand coherent structures in convective flow (Manton 1977; Lenschow and Stephens 1980; Nicholls and LeMone 1980; Greenhut and Khalsa 1982; Crum et al. 1987; Young 1988; Schumann and Moeng 1991), and the results have been compared with large-eddy simulations of the CBL (e.g., Wang and Stevens 2000). Because coherent structures in the CBL must at least partly be driven by convection, the key indicator variable must be buoyancy. Other variables have been used, including vertical velocity, temperature, and specific humidity. Lenschow and Stephens (1980) find humidity to be a good indicator of buoyant plumes in the CBL over a relatively warm ocean surface. The choice of both the indicator variable and its threshold matters (Crum and Stull 1987; Berg 2002). This choice usually depends on the data available and the specific objective of the study. For instance, Khalsa and Greenhut (1985),
Young (1988), and Berg (2002) aim to document the properties of updrafts and downdrafts in the CBL. All observational studies have used in situ (aircraft or tower) observations to characterize coherent eddies in the CBL.

This study is distinct from previous studies in that the indicator variables for conditional sampling of the CBL are measured by radar over the depth of the CBL, or a considerable portion thereof. The first indicator variable is radar reflectivity, whose spatial structure has been the basis of interpretation of CBL dynamics in many studies. Echo plumes are remarkably well defined in the CBL (Fig. 1). The high reflectivity is because of a higher density of insects (e.g., Russell and Wilson 1997). In most cases in the fair-weather CBL, these are believed to be primarily weakly flying small insects $(<10 \mathrm{~mm}$ in diameter in flight) (Geerts and Miao 2005a, hereinafter referred to as GM05). These scatterers are subject to turbulent mixing in the CBL, but they tend to converge in regions of sustained ascent, because they oppose any updrafts in which they become embedded, according to the hypothesis formulated and verified in GM05. Thus, echo plumes are expected to represent coherent eddies of rising air (Fig. 1 ), or at least regions with a history of rising motion.

A second indicator variable is the instantaneous radar-inferred vertical velocity over the depth of the CBL. In this study the thermodynamic, moisture, and vertical velocity characteristics of both "echo plumes" and "updraft plumes" are described as a way of documenting coherent structures in the CBL. The unique strength of this study is that flight-level data are available within the plumes, because the radar antennas point above and below the aircraft and the radar blind zone is small.

The data sources and data processing are described in section 2. Echo plumes are defined, and their thermodynamic properties are examined in section 3. Section 4 defines and characterizes updraft plumes.

\section{Data source and data processing}

\section{a. IHOP_2002 boundary layer flights}

Some $34 \mathrm{~h}$ of combined radar and in situ data were collected in the mature CBL in Kansas and Oklahoma in late-spring 2002 aboard the University of Wyoming King Air (WKA) aircraft. In all cases, the synoptic conditions were rather quiescent, and the $700-500-\mathrm{hPa}$ surfaces were essentially barotropic, the CBL well capped, and the skies mostly cloud free.

The WKA carried a gust probe and measured temperature and humidity at a high frequency $(25 \mathrm{~Hz})$. High-rate humidity was measured both with a Lyman- $\alpha$ 

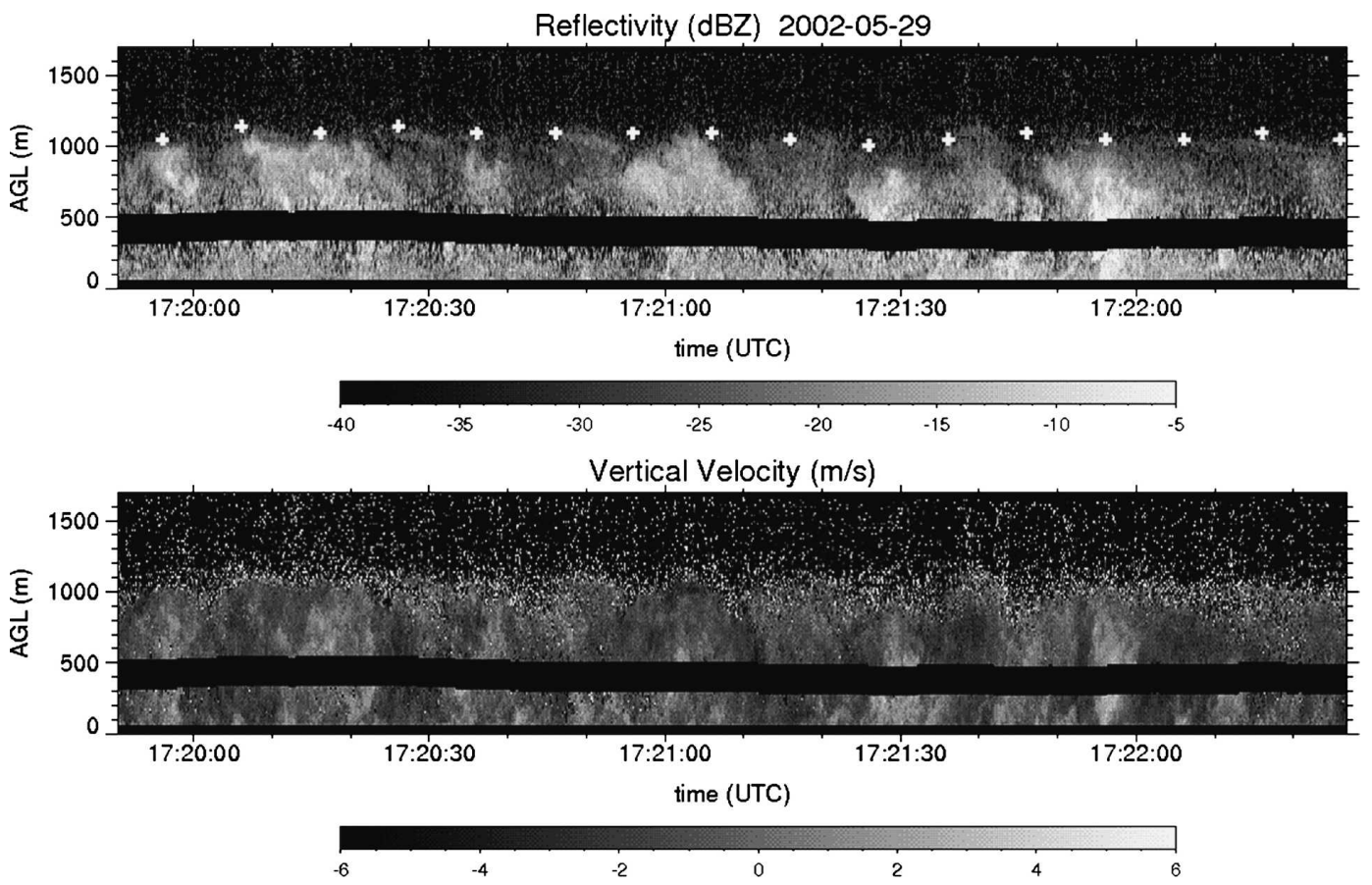

FIG. 1. Sample vertical cross section of the WCR (top) reflectivity and (bottom) vertical velocity for part of a flight leg through the CBL. Vertical axis is height above ground level, horizontal axis is time (1 min corresponds to $\sim 5 \mathrm{~km}$ ). White plus signs in the top panel indicate $z_{i_{-} \text {wCR }}$, determined based on the reflectivity minimum. The $225-\mathrm{m}$ blind zone contains the aircraft track. The aspect ratio of both images is about 2:1. The color version of this figure is available online at http://www.atmos.uwyo.edu/wcr/projects/ihop02/jam_plume_fig1.tif.

hygrometer and a Li-Cor, Inc., 6262 infrared absorption probe. Aircraft soundings from the ground to $\sim 500 \mathrm{~m}$ above the mixed layer were conducted regularly. The mature CBL was examined along three fixed tracks, each about $60 \mathrm{~km}$ long, over relatively flat terrain. During a single flight, a track was flown 12-18 times in either direction, between approximately 1300 and 1600 local solar time (LeMone et al. 2005, manuscript submitted to J. Hydrometeor., hereinafter LEM05). One of these tracks was oriented north-south in the Oklahoma Panhandle (the "western track"), over grassland, winter wheat, and sagebrush. The "central track" was eastwest oriented in south-central Kansas, over mostly grassland and winter wheat. And, the "eastern track," located $100 \mathrm{~km}$ east of the central track, contained slightly undulating land of grassland and crops. This track is the same as that used in Cooperative Atmosphere-Surface Exchange Study (CASES)-97 (LeMone et al. 2000). The WKA flew straight legs over the three tracks at several constant heights, ranging from $\sim 70 \mathrm{~m}$ AGL to just above the CBL. Above about $400 \mathrm{~m}$ AGL the flight legs followed a constant pressure level, which departed a little from a constant height AGL.

This study uses 10 flight legs along the western track on 29 May, 7 legs along the central track on 6 June, and
6 legs along the eastern track on 17 June 2002. On each of these days the wind was southwesterly, and the mean wind speed at the lowest flight legs was 4.9, 5.3, and 7.6 $\mathrm{m} \mathrm{s}^{-1}$ respectively. The mesoscale $900-\mathrm{mb}$ temperature gradient over the flight tracks pointed to the west at about 9,3 , and $6 \times 10^{-6} \mathrm{~K} \mathrm{~m}^{-1}$, respectively, producing a northerly thermal wind of $2.7,0.9$, and $1.8 \mathrm{~m} \mathrm{~s}^{-1}$ $\mathrm{km}^{-1}$, respectively. The observed wind shear within the CBL or across the CBL top was relatively weak $(<5$ $\mathrm{m} \mathrm{s}^{-1} \mathrm{~km}^{-1}$ ), and scanning ground-based radar images did not reveal any evidence for horizontal convective rolls, except on the windiest day (17 June). On that day, some linear organization is apparent (LEM05), as revealed by radar and visible satellite imagery (Fig. 2 in GM05).

The vertical air motion inferred from the WKA gust probe data is referred to as $w$. The aircraft motion is removed from the gust probe raw winds by means of aircraft speed and attitude parameters obtained from the inertial navigation system (Lenschow 1972). Further corrections are made based on multiple global positioning system receivers on the WKA. Potential temperature $(\theta)$ was derived from the reverse-flow thermometer and static pressure probe, and the water vapor mixing ratio $(r)$ was from the Lyman- $\alpha$ hygrom- 
eter, after it was calibrated by a chilled mirror dewpoint sensor, which is more accurate but has a slow response time.

\section{b. Wyoming Cloud Radar data}

The radar used here, the Wyoming Cloud Radar (WCR), is a 3-mm (95 GHz) multiantenna Doppler radar (Pazmany et al. 1994; for details about the WCR see information online at http://atmos.uwyo.edu/wcr/). The key radar configuration used for this study is the profiling mode, with fixed antennas looking up and down from the aircraft. The pulse width is $250 \mathrm{~ns}$ for the flight legs studied here, thus the gate spacing is $37.5 \mathrm{~m}$. Data are sampled at $15-\mathrm{m}$ range intervals. The first reliable radar gates are centered at 120 (nadir) and 105 (zenith) $\mathrm{m}$ from the aircraft, resulting in an $\sim 225-\mathrm{m}$ blind zone, approximately centered at flight level. For lowest flight legs (at about $70 \mathrm{~m}$ AGL), only the zenith antenna can be used, while for most flight legs in the upper CBL or above the CBL, only the nadir antenna is useful.

The along-track sampling rate corresponds with $\Delta x \cong$ $4 \mathrm{~m}$ depending on the speed of the aircraft and the radar processor load (which affects the sampling frequency, ranging between 25 and $35 \mathrm{~Hz}$ ). All in situ variables are synchronized to the WCR reflectivity and vertical velocity data at this frequency. The beamwidth (half-power width) is $9-14 \mathrm{~m}$ at a range of $1 \mathrm{~km}$ for the nadir and zenith antennas, respectively; thus the alongtrack dimension is oversampled at most ranges of interest.

The WCR antennas have a sensitivity threshold of about $-27 \mathrm{dBZ}$ at a range of $1 \mathrm{~km}$. Between echo plumes (Fig. 1), the density of scatterers is often rather low, and thus the returned power is close to the minimum detectable signal; for one flight over the western track, on 29 May 2002, the probability density function of reflectivity peaks at about $-17 \mathrm{dBZ}$ in the lower CBL, decreasing to $-27 \mathrm{dBZ}$ in the upper $\mathrm{CBL}$ (GM05). WCR data analyzed here are subjected to a simple echo detection filter: the power yielding the minimum detectable reflectivity is set to be the mean system noise plus two standard deviations. All data points with received power below this threshold are eliminated. A small but significant fraction of the CBL between plumes is below this threshold, thus the Doppler velocity spectrum is not available for the entire CBL.

The WCR Doppler velocities are corrected for aircraft motion (Leon et al. 2006). For the flights examined in this paper, Doppler velocities of the earth's surface indicate that the mean antenna-pointing angles are within $1^{\circ}$ of the vertical axis in both along- and across- track directions, such that during level flight, the radial velocities are very close to true vertical motion. The instantaneous antenna-pointing angle is usually slightly off vertical, resulting from aircraft attitude changes in turbulent air. However, it is important that the average offset from vertical be close to zero, because while contamination of the (known) horizontal aircraft motion into an off-vertical radar beam can be extracted, the contamination by the horizontal wind cannot, at least not exactly, because the horizontal wind can only be estimated, for example, from a nearby sounding. The accuracy of the WCR-inferred vertical velocity is discussed more in GM05.

The WCR vertical velocities were further adjusted for the vertical motion of scatterers relative to the air, using Eq. (2) in GM05. GM05 find that insects tend to subside (as measured by the WCR) in the presence of updrafts (as measured by the WKA gust probe). They show that this downward bias is a strong function of the vertical air motion. The adjusted WCR vertical velocities have a leg-mean uncertainty of $0.2 \mathrm{~m} \mathrm{~s}^{-1}$ (GM05), although instantaneous errors can be much larger.

\section{c. Radar-inferred CBL depth}

Echo plumes clearly mark the vertical extent of the CBL (Fig. 1). This enables an objective determination of the CBL depth $z_{i \text { wCR }}$ from the WCR reflectivity profile. The scatterer density decreases rapidly across the CBL top. Also, the radar noise, expressed in reflectivity units, increases with the square of the radar range. For these reasons we found $z_{i-\mathrm{WCR}}$ to be best defined as the level at which the zenith-beam WCR reflectivity reaches a minimum.

The high-resolution reflectivity profiles do contain local minima, because the insect density and size distribution can vary considerably among adjacent resolution volumes (section 2b). Therefore, to determine $z_{i-\mathrm{WCR}}$, reflectivity data are first averaged in the alongtrack direction for $10 \mathrm{~s}(\sim 830 \mathrm{~m})$. Further smoothening occurs in the radial direction from 15 to $45 \mathrm{~m}$, which is close to the physical gate spacing $(37.5 \mathrm{~m})$. All reflectivity averaging occurs in native units $\left(\mathrm{mm}^{6} \mathrm{~m}^{-3}\right.$, not dBZ).

In regions with very weak echoes between plumes, the resulting $z_{i \text { wCR }}$ values can be unrealistically small, for example, less than $50 \%$ of the typical $z_{i \text { WCR }}$ over plumes. Therefore, a case-specific threshold value for the profile-mean reflectivity within the CBL is assumed (e.g., $-25 \mathrm{dBZ}$ ) for a $z_{i_{-} \text {wCR }}$ estimate to be valid. To improve a few $z_{i_{-} \mathrm{WCR}}$ estimates, two more conditions are imposed: the signal-to-noise ratio must exceed $6 \mathrm{~dB}$ at $z_{i-\mathrm{WCR}}$, and the percentage of good points in the 


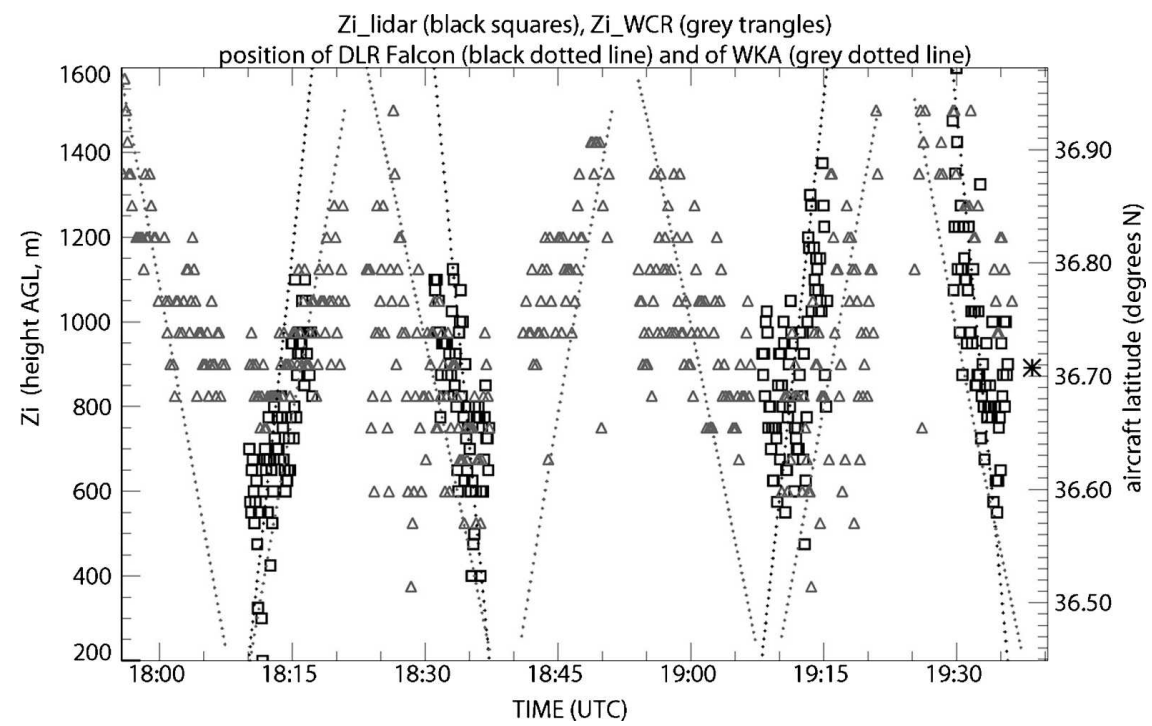

FIG. 2. Comparison of CBL depth estimates for multiple flight legs along the north-southoriented western track on 29 May 2002. The depth (shown on the left side of the graph) is estimated both by the WCR $\left(z_{i \text { wCR }}\right)$ aboard the WKA (flying at various levels within the $\mathrm{CBL}$ ), and by a backscatter lidar $\left(z_{i \_ \text {lidar }}\right)$ aboard the DLR Falcon (flying above the CBL). The latitude shown on the right side applies to the dotted lines. They show the location of both the WKA (gray dots) and the Falcon (black dots). The two aircraft travel at different speeds, but nevertheless good space-time proximity was achieved. Seven WKA and four Falcon flight legs are shown. The vertical resolution of $z_{i-W C R}$ is $45 \mathrm{~m}$. The thermodynamically inferred CBL depth is shown as well as a black star on the far right. It is based on a WKA sounding at $36.45^{\circ} \mathrm{N}$. The local solar noon at this longitude is at $1844 \mathrm{UTC}$.

averaging domain (250-350 points in the along-track direction and 3 in the radial direction) must exceed $30 \%$ at the level just below $z_{i_{-} \mathrm{WCR}}$. Values of $z_{i \_\mathrm{WCR}}$ are shown as white plus signs in Fig. 1; the CBL depth and its local variations appear to be captured well.

\section{d. Echo plumes and CBL depth}

An example of the variation of $z_{i-\mathrm{WCR}}$ is shown in Fig. 2, for a sequence of seven flight legs along the western track on 29 May 2002. This example was chosen because of the remarkable north-south gradient in CBL depth. Clearly, $z_{i \_ \text {WCR }}$ is less at the southern end of the track, where the soils were locally saturated and large puddles were present because of recent rains (LeMone et al. 2005; GM05). The CBL depth also increases slightly with time as the day progresses into the early afternoon.

Aside from this regional trend, the scatter of $z_{i \_ \text {WCR }}$ estimates around the mean at a given latitude in Fig. 2 is at least in part because of convective activity in the CBL-plumes of rising motion tend to concentrate insect scatterers and yield a deeper CBL, and compensating subsidence and/or downward entrainment tends to suppress the CBL top. The correlation coefficient between detrended $z_{i_{-} \text {WCR }}$ and WCR reflectivity (aver- aged over corresponding 10-s intervals) is $+0.46,+0.23$, and +0.16 on average for all flight legs used in this study for 29 May, 6 June, and 17 June, respectively. Cross sections such as that in Fig. 1 confirm this trend. The correlation between echo-top height and WCR vertical velocity is generally positive as well, but weaker, possibly because of a time lag between updrafts and CBL top up thrusts.

To ascertain that the echo plume top $z_{i}$ wCR corresponds to the CBL top, we compare it with the thermodynamically defined CBL depth $\left(z_{i \mathrm{TH}}\right)$ from a sounding released at "Homestead" in the middle of the western track on 29 May. The depth $z_{i_{\text {TH }}}$ is the top of the mixed layer, that is, the base of the layer marked by a rapid increase in potential temperature $\theta$. This level also marks the base of a rapid decrease in mixing ratio $q$, in this case. The $z_{i \mathrm{TH}}$ value corresponds well with $z_{i_{-} \text {WCR }}$ values at this location and time of day (Fig. 2). Backscatter lidar data have long been used to determine $z_{i}$, because the CBL top is marked by a rapid decrease of backscatter signal with height (Ferrare et al. 1991; Marsik et al. 1995; Cooper et al. 1996; White et al. 1999; Davis et al. 2000, Cohn and Angevine 2000). The $z_{i \_ \text {WCR }}$ values also compare well with backscatter lidar $z_{i}$ estimates $\left(z_{i \_ \text {lidar }}\right)$. These are derived from the 
high-resolution Doppler lidar (HRDL) on board an aircraft flying on the same track, well above the CBL (Fig. 2 ). The lidar reveals the same north-south gradient in CBL depth and the gradual deepening during the course of the day, although early on it seems to underestimate the CBL depth over the wet southern part of the track. Both the mean and the standard deviation of $z_{i \_ \text {lidar }}$ values closely match those of the $z_{i \_ \text {WCR }}$ values. One distinction is that the local CBL deepening trend during the duration of this intercomparison is larger in the lidar data than in the radar data.

In short, on fair-weather days with a well-defined CBL and sufficient scatterers, the WCR accurately measures the CBL depth and its small-scale variability. The average $z_{i}$ wCR values, based on all 23 flight legs, are 1031, 1049, and $1083 \mathrm{~m}$ on 29 May, 6 June, and 17 June, respectively. Only for the last three legs on 17 June does this height differ significantly from $z_{i \mathrm{TH}}$, which is estimated at $1240 \mathrm{~m}$ for that period (LEM05). More scatterers were present on 29 May (Figs. 1 and 2) than the two other days; on 29 May the mean reflectivity between 400 and $500 \mathrm{~m}$ AGL was $2.9 \mathrm{~dB}$ higher than on 6 June and $4.2 \mathrm{~dB}$ higher than on 17 June for all flight legs used in this study. On the last three legs of the 17 June flight, the scatterer density was insufficient to define $z_{i \_\mathrm{WCR}}$ in the interplume regions, but was still sufficient to define echo and updraft plumes and to examine their properties.

\section{Dynamical characteristics of echo plumes}

Radar studies commonly refer to echo plumes as organizing entities in the CBL (Gossard 1990). Echo patterns reflect the spatial organization of rising motion in linear and cellular convection. The tendency for air to rise in echo plumes (GM05) raises the question as to whether echo plumes are buoyant eddies, responsible for part of the vertical transport of heat, momentum, moisture, and turbulent kinetic energy across the CBL. Such eddies are the equivalent of cumulus humilis clouds in a more humid CBL. They are sometimes referred to as thermals (Scorer 1957). Stull (1988, p. 461) defines a thermal as a "large column of rising buoyant air" in the CBL; that definition is used here. Convective structures can be seen in cross sections as illustrated in Fig. 1, including anvils indicative of detrainment near $z_{i}$. It is well known that thermals and compensating motions are the dominant mode of turbulent mixing in highly convective situations (e.g., Lenschow and Stephens 1980). Therefore, we examine in situ aircraft anomalies of potential temperature, mixing ratio, buoyancy, and vertical velocity within echo plumes as possible signatures of thermals.

\section{a. Echo plume definition}

Conditional sampling techniques have been used to define and characterize CBL thermals (e.g., Lenschow and Stephens 1980; Young 1988). We use a similar technique to distinguish echo plumes from their environment based on radar reflectivity. An echo plume is defined as a region of vertically averaged radar reflectivity $(Z)$ that is some threshold value above the flight-legmean radar reflectivity $\left(Z_{m}\right)$. The vertical average comprises 14 gates of radar reflectivity for each profile (i.e., a depth of $210 \mathrm{~m}$ ). Normally the first seven nadir beam gates and the first seven zenith beam gates are used. In this case the WCR data are centered at the level of in situ data, and the averaging depth (including the 225 -m-deep blind zone) really represents $435 \mathrm{~m}$. For very low (high) flight levels in the CBL, all 14 gates had to be drawn from the zenith (nadir) beam. (Very low is defined as less than $0.3 z_{i_{-} \mathrm{WCR}}$, and very high is more than $0.7 z_{i_{-} \text {WCR. }}$ )

This averaging depth mainly represents a compromise between capturing a sufficient depth and avoiding drawbacks that come with covering the entire CBL from the ground to $z_{i_{-} \mathrm{WCR}}$. These drawbacks arise when echo plumes occupy only part of the CBL or are tilted, in which case a large averaging depth exaggerates the plume width. Consider the case of a shallow, incipient thermal. The vertically averaged reflectivity $\left(\mathrm{mm}^{6} \mathrm{~m}^{-3}\right)$ is strongly dominated by the highest values in the profile, thus it is likely that if the averaging depth were to cover the entire CBL, this incipient thermal would be labeled as an echo plume, even if the flight level is well above the actual plume and in situ measurements do not characterize this thermal.

A low-pass filter is applied to $Z$, with a cutoff wavelength of $120 \mathrm{~m}$, in order to remove the contribution of the turbulence within the inertial subrange, which is not driven by buoyancy. Young (1988) chooses $0.1 z_{i}$ as the low-pass filter cutoff wavelength for this purpose. In our case, $0.1 z_{i}$ is close to $120 \mathrm{~m}$. This horizontal distance also matches the vertical distance between the in situ data and the first radar data. We use a finite impulse response filter based on a Kaiser's window with a rather gradual cutoff in the frequency domain.

The filtered reflectivity time series for each flight leg further is detrended. We define echo plumes based on the criterion that the vertically averaged along-trackfiltered and detrended reflectivity $\left(Z_{\mathrm{df}}\right)$ be equal to or greater than a threshold value, which is a certain value $\Delta Z$ (ranging from 0 to $5 \mathrm{~dB}$ ) greater than $Z_{m}$, over a distance of at least $120 \mathrm{~m}$. The value $\Delta Z$ is referred to as the (threshold) plume strength. Background or "interplume" regions are defined as the segments where 


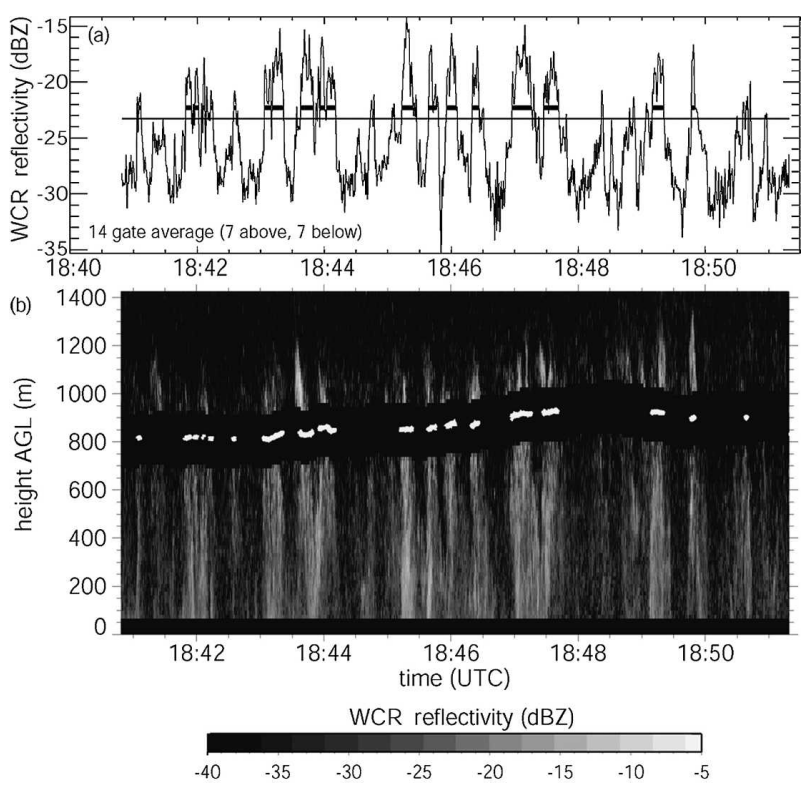

FIG. 3. (a) Illustration of echo plume definition, for a $55-\mathrm{km}$ long flight leg on 29 May 2002 across the western track. The black curve is the vertically averaged and filtered reflectivity $\left(Z_{f}\right)$, the straight, level line is the leg-mean value of reflectivity $\left(Z_{m}\right)$, and the thick bars above the mean show the position of echo plumes with a plume strength $\Delta Z$ of $1 \mathrm{~dB}$. (b) Corresponding vertical cross section of radar reflectivity, highly compressed in the horizontal direction (aspect ratio $\sim 13: 1$ ). One minute of data corresponds to a distance of $\sim 5 \mathrm{~km}$. Segments designated as plume (white) are indicated by the line at the WKA flight level in the middle of the blind zone.

$Z_{\mathrm{df}}$ is less than the specified threshold. Plumes less than $120 \mathrm{~m}$ wide are not counted as echo plumes, thus they are included in the background.

An example of the filtering and thresholding procedure is shown in Fig. 3 for a flight leg flown at $\sim 800 \mathrm{~m}$ above the surface over the western track. The procedure nicely captures the echo plumes apparent in Fig. $3 \mathrm{~b}$, especially those that are continuous across the blind zone, that is, the objectively defined echo plumes are very close to those resulting from visual inspection of the cross section. This method is applied to all 23 flight legs used in this study.

\section{b. Echo plume size characteristics}

Echo plumes have a range of widths and spacings. We normalize these horizontal dimensions by the CBL depth, estimated as the leg-mean value of $z_{i \text { wCR }}$, except for the three last legs on 17 June, where we used $z_{i \_ \text {TH }}$ from WKA soundings $(1240 \mathrm{~m})$. The likelihood of finding a plume, or an interplume region, of a given size roughly decays exponentially with size (Fig. 4). The most common size is the smallest one resolved. The widest plumes are about $2.5 \mathrm{~km}$, which is a small frac-

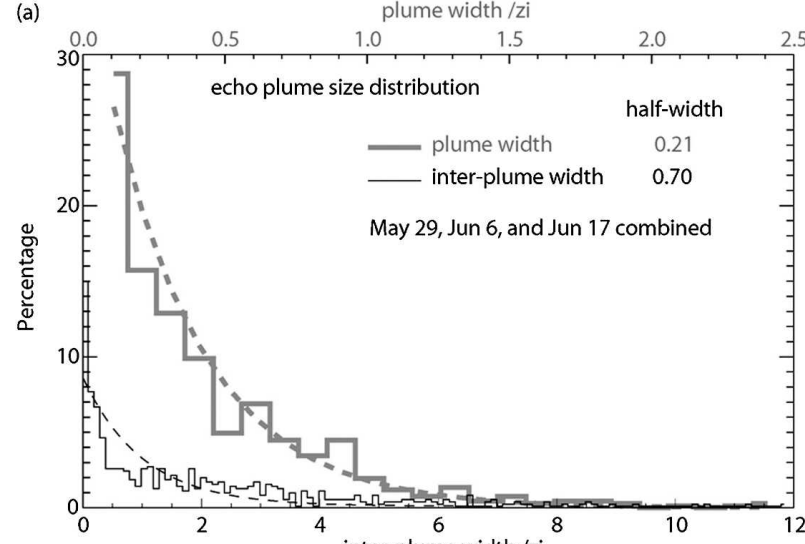

(b)

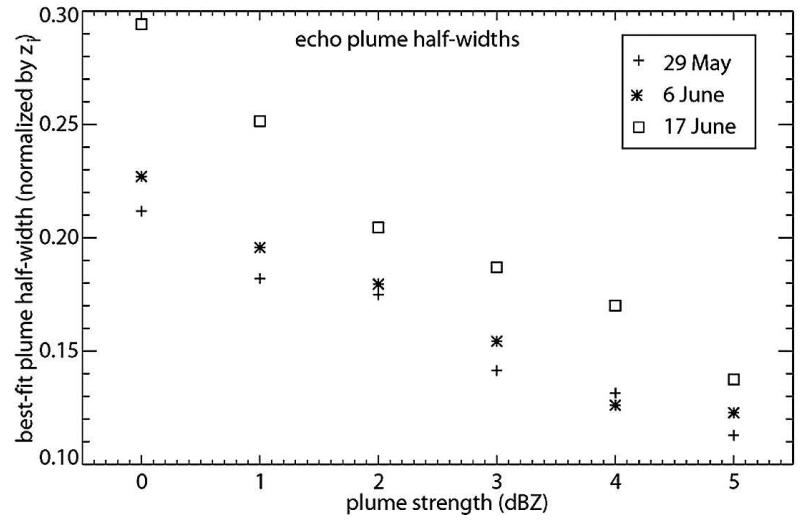

FIG. 4. (a) Histograms of the width of echo plumes and of interplume regions (i.e., background). The width is normalized by the local CBL depth, and the bin size is $0.1 z_{i}$. Plumes are defined here at $\Delta Z=+1 \mathrm{~dB}$. The frequencies are expressed as percentages. The histograms include the data from 23 flight legs on 3 days. The dashed lines are the best-fit exponential curves. (b) Variation of half-width of the best-fit exponential curve with plume strength $\Delta Z$, for 3 days.

tion of the total length of the flight leg. A useful parameter for the observed distributions is the "halfwidth," which is the distance at which the best-fit exponential curve attains 0.5 times the value of the smallest resolvable scale (comparable to the "half life" of unstable isotopes). Assuming a plume strength $\Delta Z=$ $1 \mathrm{~dB}$, the half-width of echo plume distribution is about one-third of that of interplume regions, that is, the space between the end of one plume and the beginning of the adjacent plume. The true plume spacing, measured from/to the center of adjacent plumes, is the sum of the interplume spacing and two halves of plumes, and its reciprocal is the number of plumes per unit distance. Using the half-width numbers given in Fig. 4a as representative values of plume and interplume widths, the true plume spacing $(0.70+2 \times 0.21 / 2=$ 0.91) is close to the CBL depth itself; in other words there is about one plume per kilometer. 


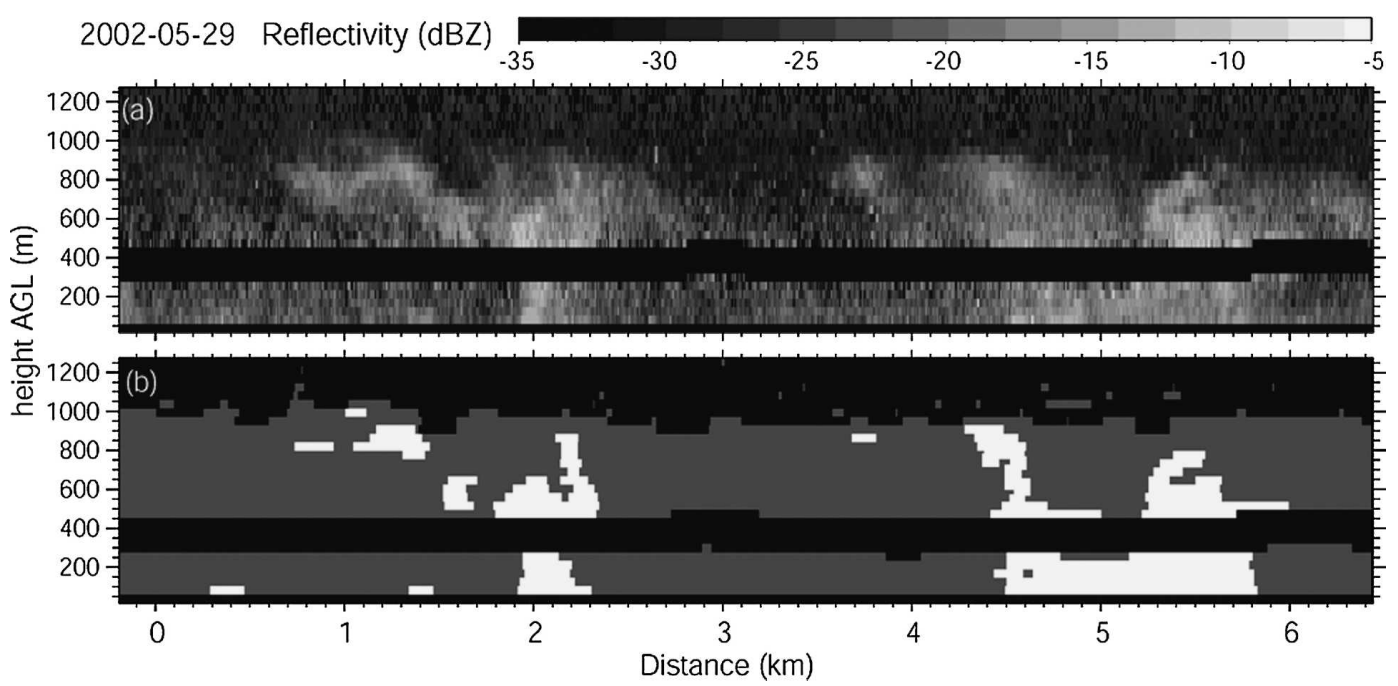

FIG. 5. Illustration of echo plume definition in two dimensions. (a) Radar reflectivity in a vertical transect (plotted at a 1:1 aspect ratio), and (b) corresponding echo plumes at $\Delta Z=1 \mathrm{~dB}$ are shown in white. The background is gray, and the radar blind zone and echo-free zone are black.

Echo plumes tend to be more narrow than the CBL depth, thus their aspect ratio (height: width) tends to be larger than 1.0. Clearly, plumes become narrower and the interplume regions wider when a more restrictive plume definition is used. At a plume strength $\Delta Z=1$ $\mathrm{dB}, 21 \%$ of the $\mathrm{CBL}$ is in plume and $79 \%$ is interplume. This is an average for data from 23 flight legs examined here, but the numbers are very consistent among these 3 days. At $\Delta Z=3 \mathrm{~dB}$, the in-plume percentage is $12 \%$; at $\Delta Z=5 \mathrm{~dB}$ it is $6 \%$. The echo plume size distribution contines to resemble an exponential curve, and the plume half-width for the best-fit exponential curve decreases more or less linearly over this range of plume strengths (Fig. 4b).

The 2D structure of plumes can be described as well, using basically the same method used to define plumes based on $Z_{m}$ (section 3a), but employing reflectivity data at all heights. First, the reflectivity is averaged every three profiles and every three radar gates, yielding a grid with a resolution of about $12 \times 45 \mathrm{~m}^{2}$. Then the reflectivity is low-pass filtered in the along-track direction, with a cutoff wavelength of $120 \mathrm{~m}$, at each height separately; thus the smallest resolved 2D plume is $120 \times 45 \mathrm{~m}^{2}$. Plumes are defined as segments with some threshold reflectivity above the flight-leg-mean reflectivity at each height. This is illustrated in Fig. 5 for a threshold of $+1 \mathrm{~dB}$. Echo plumes evident in Fig. 5a are captured well in the binary analysis (Fig. 5b). They are spatially rather continuous entities, even across the blind zone, although some plumes do not occupy the full depth of the CBL.

We can use this $2 \mathrm{D}$ plume definition to estimate the variation with height of the typical plume width and interplume spacing; changes in the width and especially the number of plumes with height can affect flight-legmean plume thermodynamic anomalies. These anomalies, discussed below, will be plotted as a function of flight level, and the interpretation assumes that the population of plumes is roughly the same at each level. Our analysis over 3 days shows that the normalized plume width tends to increase slightly with height within the CBL (Fig. 6), as has been observed elsewhere for thermals (Kaimal et al. 1976; Lenschow and

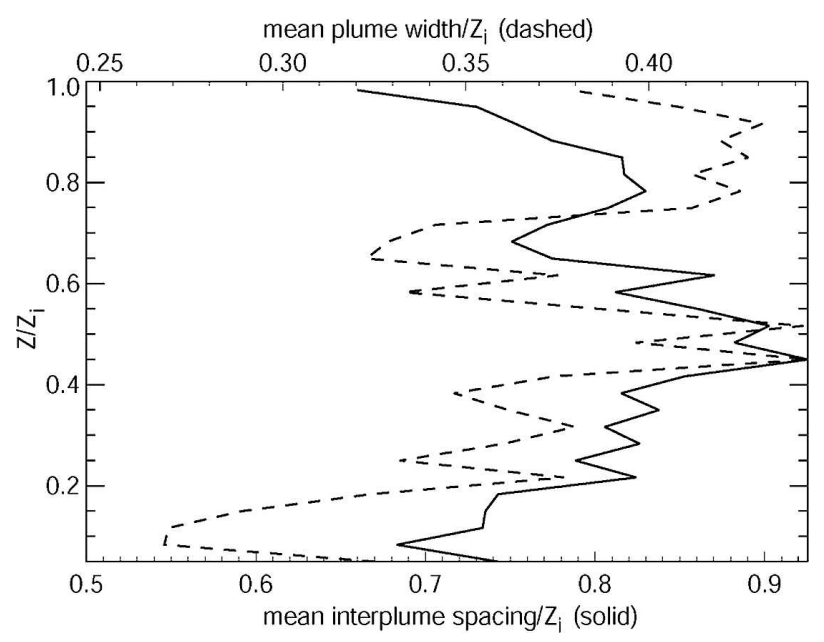

FIG. 6. Variation with height (in the CBL) of the mean plume width (dashed) and interplume spacing (solid). Both are normalized by $z_{i}$. The analysis is based on 2D echo plumes with a plume strength $\Delta Z$ of $1 \mathrm{~dB}$, where $Z_{m}$ is height dependent. The values are averages for 23 flight legs on 3 days. 
Stephens 1980). The spacing between plumes also slightly increases with height, at least in the lower half of the CBL (Fig. 6). Thus, the number of plumes must decrease with height, specifically from about 5 to 4 (10 $\mathrm{km})^{-1}$ between the lower and the upper CBL (not shown). This can be due either to anvil merger or to shallow plumes not (yet) reaching the CBL top. Examples of both can be found in the cross sections.

\section{c. Thermodynamic and kinematic properties of echo plumes}

We now evaluate in-plume anomalies of several in situ variables, namely, mixing ratio $\left(r^{\prime}\right)$, potential temperature $\left(\theta^{\prime}\right)$, virtual potential temperature $\left(\theta^{\prime}{ }_{v}\right)$, and vertical air velocity $\left(w^{\prime}\right)$. All of these variables are lowpass filtered (using the same minimum wavelength of $120 \mathrm{~m}$ ) and detrended before computing the in-plume anomalies, denoted with a prime ('). These anomalies are shown in Fig. 7 in terms of plume strength $\Delta Z$.

In the absence of liquid or solid water, and ignoring pressure perturbations, the buoyancy $B\left(\mathrm{~m} \mathrm{~s}^{-2}\right)$ can be partitioned in a temperature term and a water vapor term (e.g., Doswell and Markowski 2004),

$$
B=g \frac{\theta_{v}^{\prime}}{\bar{\theta}_{v}} \cong g\left(\frac{\theta^{\prime}}{\bar{\theta}}+0.61 r^{\prime}\right),
$$

where the overbars refer to detrended leg-mean values. Thus, the buoyancy force is linearly proportional to $\theta_{v}^{\prime}$. For 10 flight legs on 29 May, echo plumes are generally buoyant $\left(\theta_{v}^{\prime} \cong+0.12 \mathrm{~K}\right)$ (Fig. 7a). The leg-to-leg variability is high however, which is mainly attributable to flight level within the CBL, as discussed below. The buoyancy is largely because of excess water vapor in plumes, that is, the second term in Eq. (1) $\left(r^{\prime} \cong+0.6 \mathrm{~g}\right.$ $\mathrm{kg}^{-1}$ ). The plumes are not anomalously warm, in fact at low plume strength, plumes tend to be slightly cooler than the background $\left(\theta^{\prime} \cong-0.02 \mathrm{~K}\right)$. All anomalies increase as the plume strength $\Delta Z$ increases from 0 to 5 $\mathrm{dB}$; that is, more-defined echo plumes are more buoyant.

The plume buoyancy is remarkably similar for seven flight legs on 6 June (Fig. 7b), and for six flight legs on $17 \mathrm{June}$ (Fig. 7c); $\theta_{v}^{\prime}$ is positive and gains about $+0.5 \mathrm{~K}$ as $\Delta Z$ increases in the range of $0-5 \mathrm{~dB}$. However, on these days the buoyancy is only partly because of excess water vapor in the plumes $\left(0.2-0.4 \mathrm{~g} \mathrm{~kg}^{-1}\right)$; the water vapor term explains $\sim 55 \%$ of the buoyancy on 6 June and $\sim 40 \%$ on 17 June. The remainder of the buoyancy is because of excess warmth in the plumes $\left(\theta^{\prime}<0.1 \mathrm{~K}\right)$. The mean mixing ratio was highest on $17 \mathrm{June}$, and only on this day were a few very small cumuli present in the upper CBL. One unexpected observation is that the water vapor excess in the plumes slightly decreases with increasing plume strength on this day; it is not clear why this is, but the 17 June sample was the smallest in size (fewest flight legs and shortest leg length). Especially at high plume strength, few plumes were sampled.

The air tends to rise in plumes (Fig. 7), consistent with the positive buoyancy there, on all 3 days. Updrafts tend to be stronger on days with higher plume buoyancy, although the differences in mean plume buoyancy and updraft strength between the 3 days are small. The increase of updraft strength with plume strength is consistent with the corresponding buoyancy change. Is the observed buoyancy, $\sim 0.12 \mathrm{~K}$ at $1-\mathrm{dB}$ plume strength, sufficient to explain the observed updraft speed? The mean value of $w^{\prime}$ at the $1-\mathrm{dB}$ plume threshold ranges from $1.0 \mathrm{~m} \mathrm{~s}^{-1}$ on 29 May to $1.5 \mathrm{~m} \mathrm{~s}^{-1}$ on 17 June. The height over which an undiluted parcel with the observed buoyancy (unopposed by pressure perturbation gradient forces) gains an updraft of 1.0 $1.5 \mathrm{~m} \mathrm{~s}^{-1}$ is only $132-296 \mathrm{~m}$, that is, far less than the CBL depth. In other words, the magnitude of the plume buoyancy appears sufficient to produce the observed updrafts. The magnitudes of $\theta_{v}^{\prime}$ and $w^{\prime}$ in Fig. 7 are similar to those for thermals as documented by Lenschow and Stephens (1980). Their profiles (shown in their Fig. 4) are normalized by the surface fluxes, but upon scaling the variables, they find values of $r^{\prime}$ of $\sim 0.3$ $\mathrm{g} \mathrm{kg}^{-1}, \theta^{\prime}$ of $\sim 0.15 \mathrm{~K}$, and $w^{\prime}$ of $\sim 1.0 \mathrm{~m} \mathrm{~s}^{-1}$ in thermals.

\section{d. Variation of plume characteristics with height in the $C B L$}

In section $3 \mathrm{c}$, average properties of echo plumes were examined. We now describe the variation of plume properties inferred from individual flight legs as a function of height in the CBL. Water vapor excess in plumes tends to be height independent (Fig. 8a), except near the CBL top, where some large water vapor anomalies occur, presumably because of the entrainment of dry free-tropospheric air into the CBL between plumes. This is more pronounced on 29 May than on the other 2 days. That can be explained by the large drying across the CBL top on 29 May; sounding data indicate a vertical mixing ratio difference of $4-5 \mathrm{~g} \mathrm{~kg}^{-1}$ across an $\sim 200$-mdeep stable layer above the CBL (Fig. 3 in GM05), which is about 2 times as large as on 6 and 17 June.

Similarly, $\theta^{\prime}$ tends to be positive at low levels and become negative in the upper CBL (Fig. 8b). Unfortunately, none of the flight levels fall between $0.8 z_{i}$ and $1.0 z_{i}$, but the rapid decrease of in-plume $\theta^{\prime}$ in the highest flight levels indicates that high- $\theta$ air from above the CBL entrains rather far down between plumes, at least to $0.7 z_{i}$. 


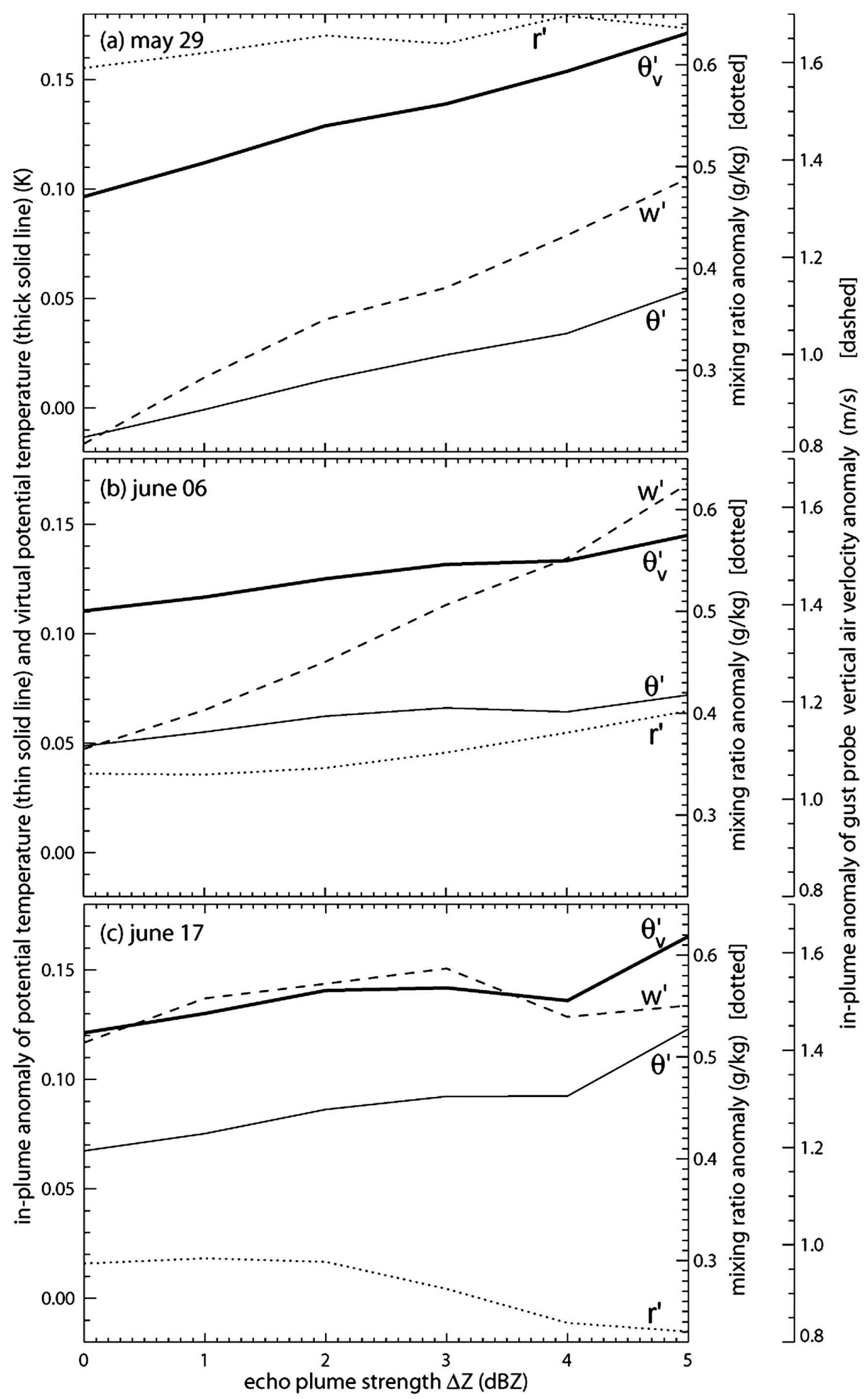

FIG. 7. Thermodynamic characteristics of echo plumes, plotted as a function of plume strength, for (a) 29 May, (b) 6 Jun, and (c) 17 Jun. Thin (thick) solid lines show the (virtual) potential temperature anomaly, dotted lines show mixing ratio anomaly, and dashed lines show gust probe vertical air velocity anomaly. The anomalies are differences between plume and interplume regions. 

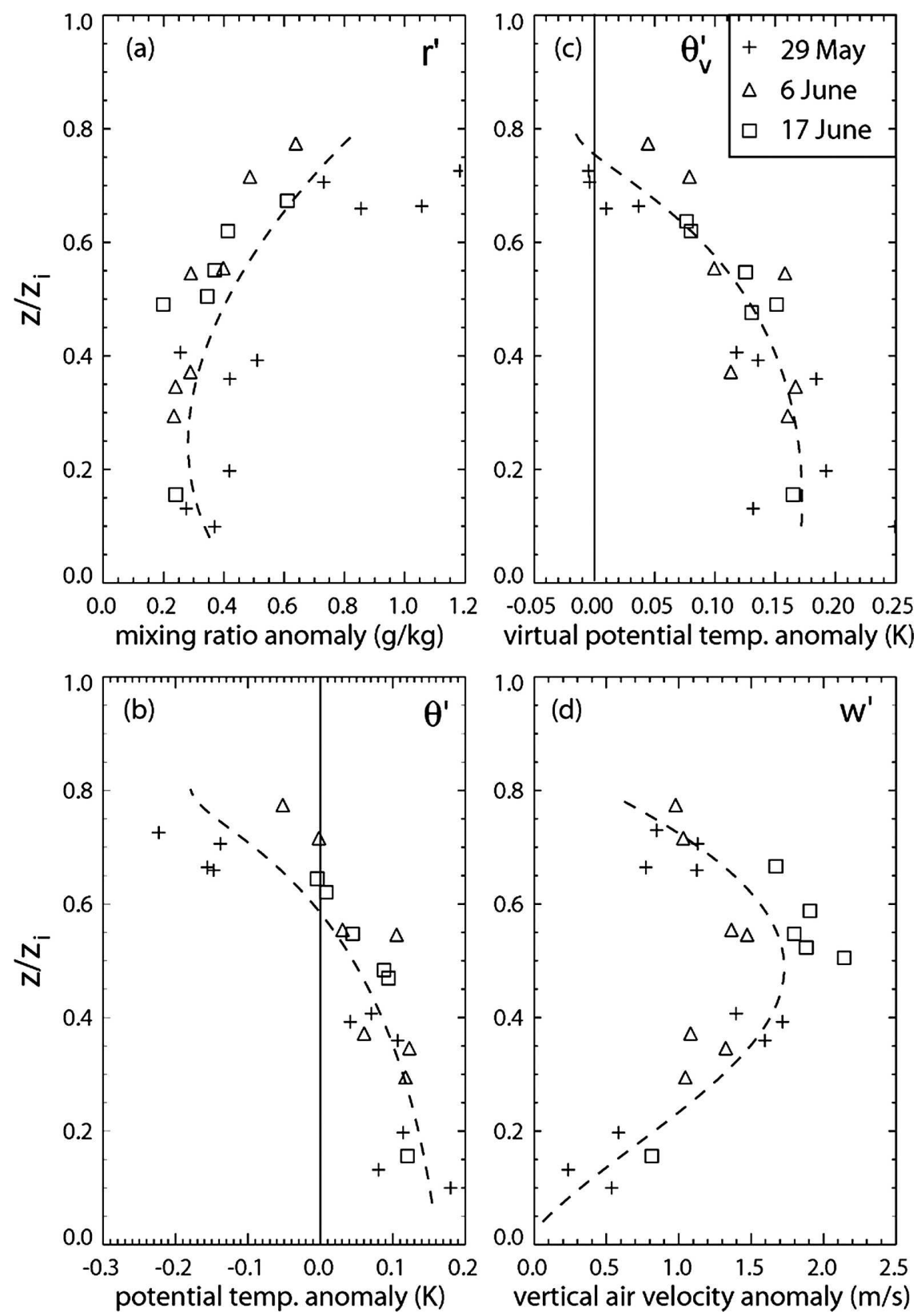

FIG. 8. Vertical variation of echo plume characteristics. Plumes are defined based on $\Delta Z=$ $1 \mathrm{~dB}$. The height is shown relative to the flight-leg mean $z_{i \text { wCR }}$. Each symbol represents one flight leg. The vertical air velocity is based on gust probe data. The dashed curves are subjectively interpolated.

In a well-mixed BL, capped by a drier free atmosphere, the in-plume $\theta^{\prime}$ tends to decrease with height because $d \bar{\theta} / d z>0$, and vice versa for $r^{\prime}$, because $d \bar{r} / d z$ $<0$ across the CBL top (the overbar refers to a basic state). Edwards (2004) confirms these vertical trends for 29 May by plotting $\theta$ and $r$ from surface stations along the flight track and from all WKA flight legs, as a function of height AGL, and averaged for 1-h time blocks. These opposite vertical trends imply that $\theta_{v}^{\prime}$ is less height dependent [see Eq. (2)]. The buoyancy is expected to be due more to temperature at low levels and to water vapor higher in the CBL (Nicholls and LeMone 1980). Indeed, comparing Figs. 8a, 8b, and 8c, it is clear that at lower levels plume buoyancy $\left(\theta_{v}^{\prime} \cong\right.$ $+0.15 \mathrm{~K})$ is largely because of excess warmth $\left(\theta^{\prime} \cong\right.$ $+0.10 \mathrm{~K}$ ), while at higher levels (above $0.6 z_{i}$ ) the 

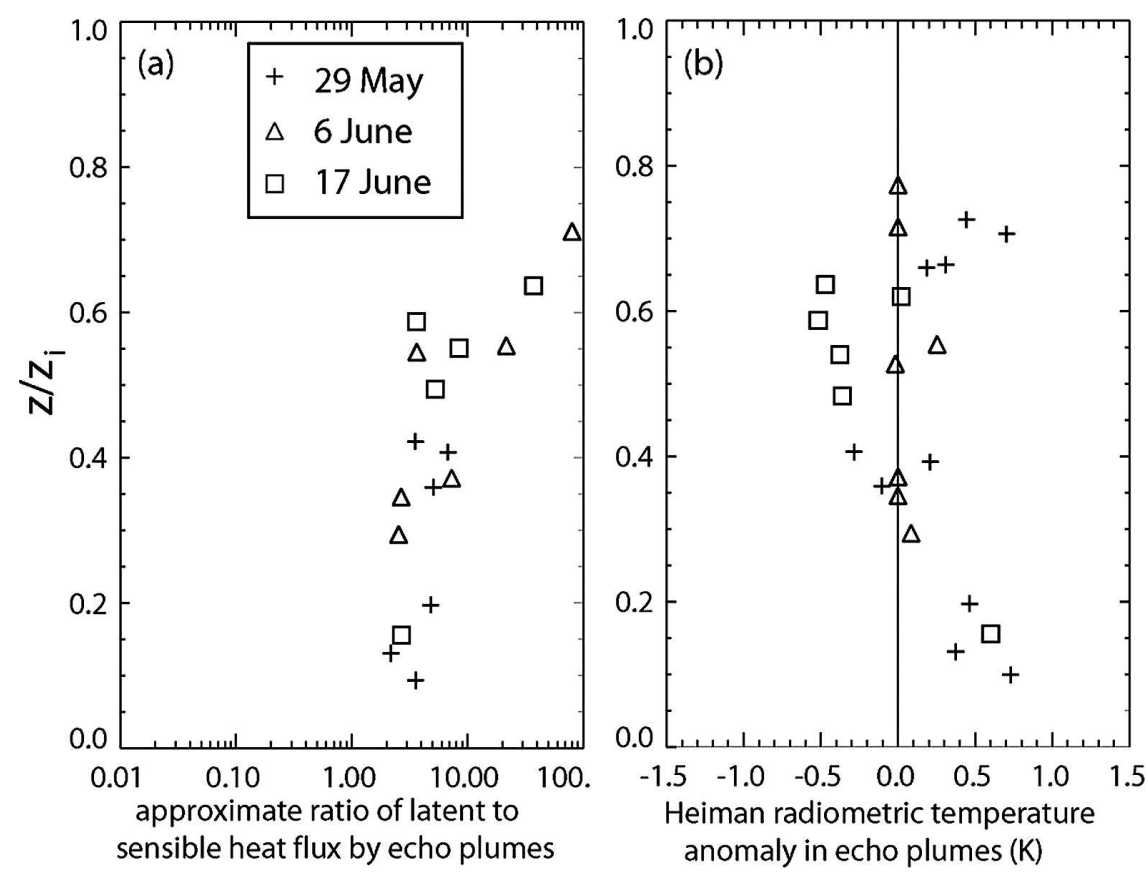

FIG. 9. As Fig. 8, but for the (a) approximate Bowen ratio and (b) upwelling infrared brightness temperature anomaly. Latent and sensible heat fluxes are calculated from the data in Fig. 8. The flight legs with a negative $w^{\prime} \theta^{\prime}$ are not shown in (a).

plumes lose their warmth $\left(\theta^{\prime}<0\right)$ yet remain positively buoyant for some time because of their excess humidity $\left(r^{\prime}>0\right)$. We find that below $0.6 z_{i}$, while $\theta^{\prime}$ does decrease slightly with height, $r^{\prime}$ remains rather constant, and as a result buoyancy decreases slightly, consistent with the conceptual image of an entraining thermal. Extrapolated values of $\theta_{v}^{\prime}$ become negative close to $0.8 z_{i}$ (Fig. 8c).

The plume vertical velocity profile (Fig. 8d) is broadly consistent with the plume buoyancy: average plume updrafts strengthen with height from an extrapolated $0 \mathrm{~m} \mathrm{~s}^{-1}$ at the ground to a maximum near $0.5 z_{i}$, where the plume buoyancy starts to rapidly decrease. The vertical profiles of $r^{\prime}, \theta^{\prime}$, and $w^{\prime}$ correspond well to those in Lenschow and Stephens (1980).

Because echo plumes are both anomalously moist and warm (at least in the lower CBL) and tend to be associated with updrafts, they must contribute to the upward flux of both heat and moisture, simultaneously, even under the observed heterogeneous land surface conditions (e.g., LeMone et al. 2003). To assess the vertical profile of heat fluxes by the coherent eddies that produce echo plumes, we take the products $\theta^{\prime} w^{\prime}$ (a surrogate for sensible heat flux by plumes) and $r^{\prime} w^{\prime}$ (latent heat flux). The former slightly increases up to $0.4 z_{i}$ and decreases with height above this level, becoming negative above $0.6 z_{i}$ (not shown).
The product $r^{\prime} w^{\prime}$, on the other hand, rises at all levels with flight data by a factor of 4 between $0.1 z_{i}$ and $0.7 z_{i}$. This may imply that the latent heat flux by the plume-generating eddies rapidly increases with height, whereas the sensible heat flux decreases with height above $0.4 z_{i}$. This is in agreement with flightlevel turbulent flux measurements (LEM05). Also, the ratio of latent heat to sensible heat $\mathrm{LE} / H \sim L r^{\prime} w^{\prime}$ l $\left(C_{p} \theta^{\prime} w^{\prime}\right)$ is larger than 1 (Fig. 9a) and increases with height, indicating that the latent heat flux by coherent eddies increasingly exceeds the sensible heat flux. This too is consistent with airborne eddy flux measurements. Here $L$ is the latent heat of condensation and $C_{p}$ is the specific heat of air under constant pressure.

In summary, this basic characterization suggests that echo plumes correspond with the conceptual image of CBL thermals. Clear-air thermals lose their buoyancy gradually at first, and rapidly in the upper part of the CBL (Lenschow and Stephens 1980; Young 1988). The negative buoyancy of plumes near $z_{i}$ reflects both the overshooting/detrainment of plumes, and subsidence/ entrainment of free-tropospheric air between the plumes. Significant variance exists in the properties of individual echo plumes, which may be due in part to a time lag between the dynamics and the radar reflectivity signal (which results from insect convergence). Such a 

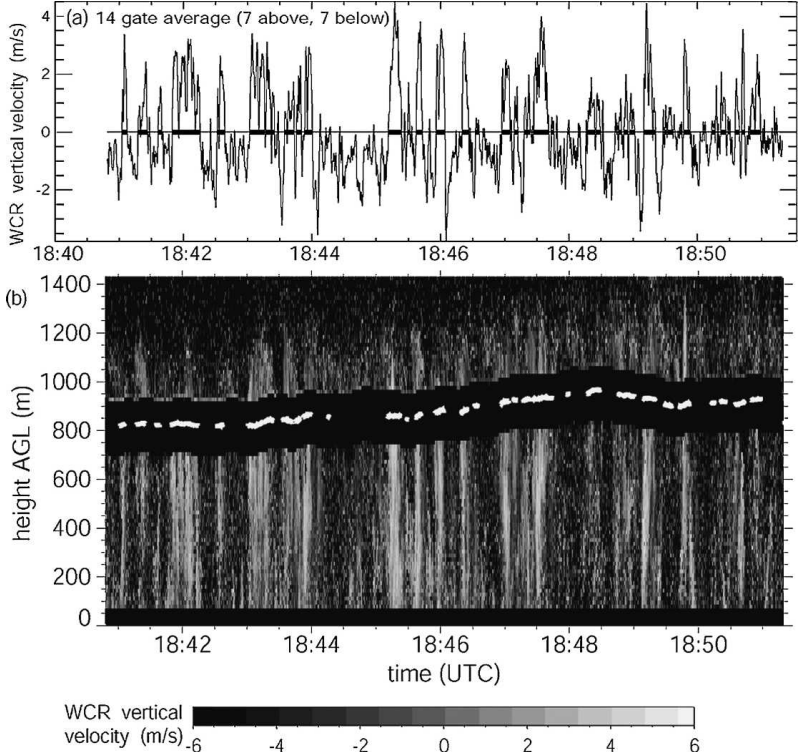

FIG. 10. An illustration of the definition of updraft plumes for the same flight leg shown in Fig. 3. (a) Time series of filtered gust probe vertical velocity $w_{f}$ (gray line) and its leg-mean value $w_{m}$ (thin straight line). The thick bars on this line show the position of updraft plumes for a plume strength $\Delta V$ of $0.0 \mathrm{~m} \mathrm{~s}^{-1}$. (b) Corresponding vertical cross section of WCR vertical velocity, with locations of updraft plumes as thick white lines in the blind zone.

time lag becomes important if it is significant relative to the typical lifespan of a thermal.

\section{Characteristics of updraft plumes}

\section{a. Updraft plume definition}

We now define updraft plumes and compare them with reflectivity-defined plumes. Observational studies (e.g., Young 1988; Khalsa and Greenhut 1985) and numerical simulations (e.g., Berg 2002) have used vertical air velocity as the indicator variable in the definition of CBL thermals. This study has the advantage that the vertical air motion can be estimated not just at flight level but also in the vertical dimension by means of WCR Doppler data above and below the aircraft. Thus we use the method discussed in section 3a using radar vertical velocity instead of reflectivity. WCR vertical velocities were averaged over the 14 closest range gates- 7 above and 7 below the aircraft, low-pass filtered (using the same threshold wavelength of $120 \mathrm{~m}$ ), and detrended $\left(w_{\mathrm{df}}\right)$. An "updraft plume" is defined as a continuous section of flight leg at least $120 \mathrm{~m}$ wide with $w_{\mathrm{df}}$ equal to or greater than a threshold value, which is chosen to be the flight-leg mean $\left(w_{m}\right)$ plus a certain value $\Delta V$. The parameter $\Delta V$ is referred to as the updraft plume strength, and it ranges between 0.0 and $1.0 \mathrm{~m} \mathrm{~s}^{-1}$.
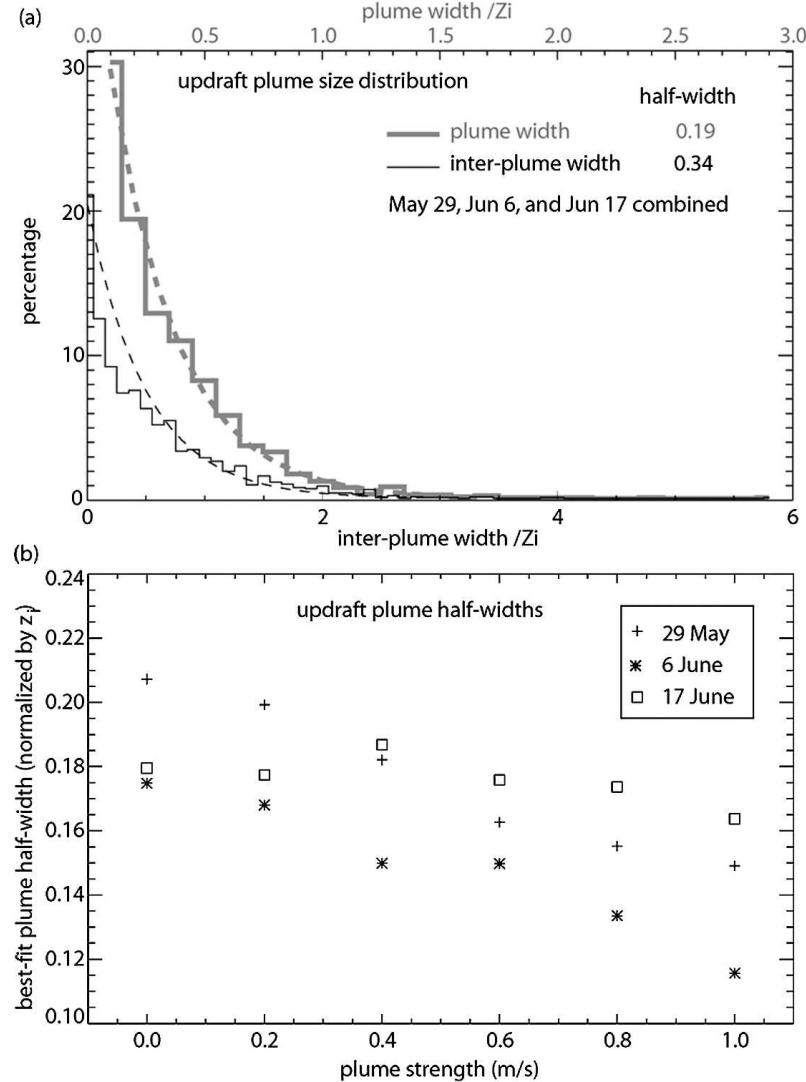

FIG. 11. As in Fig. 4, but for updraft plumes. In (a) the assumed plume strength $\Delta V$ is $0.0 \mathrm{~m} \mathrm{~s}^{-1}$.

\section{b. Updraft plume size characteristics}

The definition of updraft plumes is illustrated in Fig. 10. Reflectivity-defined plumes for the same cross section (Fig. 3) do mostly coincide with updraft plumes, both in width and location. The size distribution of updraft plumes decays exponentially, as for echo plumes, but updraft plumes tend to be narrower than echo plumes (Fig. 11). Clearly plume width strongly depends on plume definition (i.e., the assumed plume strength), but even under the weakest definition of updraft plumes $(\Delta V=0)$, the half-width of these plumes $\left(0.19 z_{i}\right)$ is less than the half-width of echo plumes $\left(0.21 z_{i}\right.$ at $\left.\Delta Z=1 \mathrm{~dB}\right)$. The half-width of updraft plumes decreases roughly linearly with increasing plume strength $\Delta V$ (Fig. 11b), as for echo plumes, but the decay is more gradual than for echo plumes (Fig. 4b). For very well-defined plumes, say those that occupy only $6 \%$ of the CBL (i.e., for $\Delta Z=5 \mathrm{~dB}$ and $\Delta V=1$ $\mathrm{m} \mathrm{s}^{-1}$, approximately), both updraft plumes and echo plumes are about equally narrow, with a best-fit plume half-width of about $0.14 z_{i}$.

The spacing between echo plumes is significantly larger than the updraft plume spacing, that is, updrafts 
are more numerous. Clearly, as the definition of an updraft plume becomes more restrictive, the spacing between updrafts increases. The difference between typical echo and updraft plume spacing applies for all echo and updraft plume strengths, although the ratio of echo: updraft interplume half-width decreases from 2.5 for the weakest plumes $\left(\Delta Z=0 \mathrm{~dB}\right.$ and $\left.\Delta V=0 \mathrm{~m} \mathrm{~s}^{-1}\right)$ to 1.5 for the strongest plumes $(\Delta Z=5 \mathrm{~dB}$ and $\Delta V=$ $1 \mathrm{~m} \mathrm{~s}^{-1}$ ). The difference in spacing is evident also in comparing Fig. 3 with Fig. 10. Clearly large sections exist without clear echo plumes, but with some updraft plumes.

In short, updrafts tend to be both narrower, and more numerous than echo plumes. One explanation is that reflectivity is the result of a history of updrafts in the CBL, that is, that the insect response time is relatively long in comparison with the lifespan of a thermal. Possibly the updrafts without clear echo plumes are very young ones. It is conceivable that insect concentrations only rise gradually in a developing updraft, because it is unlikely that insects move horizontally toward this updraft. Evidence exists that concentrations increase because insects, carried by air mass convergence, find themselves caught in an updraft and then oppose this rising air motion. Assuming a steady-state 2D circulation of representative strength, Geerts and Miao (2005b) find that insect concentrations settle in updrafts after 30-60 min. It would take about the same time for insects to disperse again after that circulation has been turned off.

The dimensional properties of updraft plumes can be compared indirectly with results from other studies. Melling and List (1980) and Young (1988) also found updraft widths in the CBL to be lognormally distributed. However, Young mentioned that the lognormal distribution might be caused by removing small drafts by the smoothing process. In our case, the plume width distribution peaks in the first bin $\left(0.1-0.2 z_{i}\right)$ for both echo plumes (Fig. 4a) and updraft plumes (Fig. 11a). The average number of updraft plumes per unit distance and the plume width compare well with estimates by Lenschow and Stephens (1980) for corresponding updraft sizes, if their normalized data are scaled by observed surface fluxes. They use flight-level data, in particular, vertical velocity and thermodynamic data, to characterize a rather shallow CBL.

\section{c. Thermodynamic properties of updraft plumes}

Thermodynamically updraft plumes are broadly similar to echo plumes (Fig. 12). Updraft plumes contain excess water vapor (although some $0.1-0.2 \mathrm{~g} \mathrm{~kg}^{-1}$ less than echo plumes on the three respective days), and about $0.04-0.11 \mathrm{~K}$ in excess warmth, and these anoma- lies generally increase as the updraft plume becomes more defined. As a result, updraft plumes are positively buoyant on all 3 days, with an average magnitude of $0.09 \mathrm{~K}$ at $\Delta V=0 \mathrm{~m} \mathrm{~s}^{-1}$ increasing to $0.12 \mathrm{~K}$ at $\Delta V=0.5$ $\mathrm{m} \mathrm{s}^{-1}$ and $0.15 \mathrm{~K}$ at $\Delta V=1.0 \mathrm{~m} \mathrm{~s}^{-1}$. The contribution of $\theta^{\prime}$ to buoyancy [first term in Eq. (1)] is generally somewhat larger for updraft plumes than for echo plumes (Fig. 7). It is smallest on 29 May $(\sim 40 \%)$ and largest on 17 June (ranging from $68 \%$ to $80 \%$, depending on updraft definition), matching what we found for echo plumes. The consistency of thermodynamic properties of updraft plumes with those of echo plumes is confirmed by the positive reflectivity anomalies found coincident with updraft plumes, and the tendency of those anomalies to strengthen as $\Delta V$ increases.

The vertical variation of thermodynamic and kinematic properties of updraft plumes is also similar to that for echo plumes. The profiles shown in Fig. 13 display the properties for any updraft $(\Delta V=0)$. Clearly the anomalies are stronger and more consistent for more restrictively defined updraft plumes. In the lower and middle CBL (between $0.1 z_{i}$ and $0.7 z_{i}$ ), $r^{\prime}$ is scattered, revealing no trend, while $\theta^{\prime}$ shows a negative trend, consistent with Nicholls and LeMone (1980). Above $0.7 z_{i}$, the anomalies reveal the influence of the drier, potentially warmer free troposphere. At very low levels, updraft plumes tend to have more excess warmth $\left(\theta^{\prime}>0.2 \mathrm{~K}\right)$, and thus $\theta_{v}^{\prime}$ is highest near the ground. The decrease of positive buoyancy with height in the CBL suggests that these updrafts are entraining thermals.

Interestingly, the upwelling IR temperature anomaly within updraft (or echo) plumes is also highest for the lowest flight levels, about $+0.7 \mathrm{~K}$ for echo plumes (Fig. $9 \mathrm{~b}$ ) and $+0.4 \mathrm{~K}$ for updraft plumes. This temperature is measured by a nadir-pointing Heiman radiometer and is a measure of the underlying land or "skin" surface temperature. (For these low-level flight legs, the contribution of the interstitial air to the upwelling IR is insignificant.) This suggests that the spatial organization of plumes may well be affected by the heterogeneity of the land surface in this largely agricultural region, at least at low levels (LEM05).

\section{Discussion}

The consistency of thermodynamic properties between updraft plumes and echo plumes suggests that echo plumes generally correspond with columns of rising, buoyant air. Better-defined echoes tend to correspond with more vigorous thermals. The broader implication is that clear-air echoes mapped by operational weather radars within the CBL represent the dynamical organization of the CBL reasonably well. This has im- 


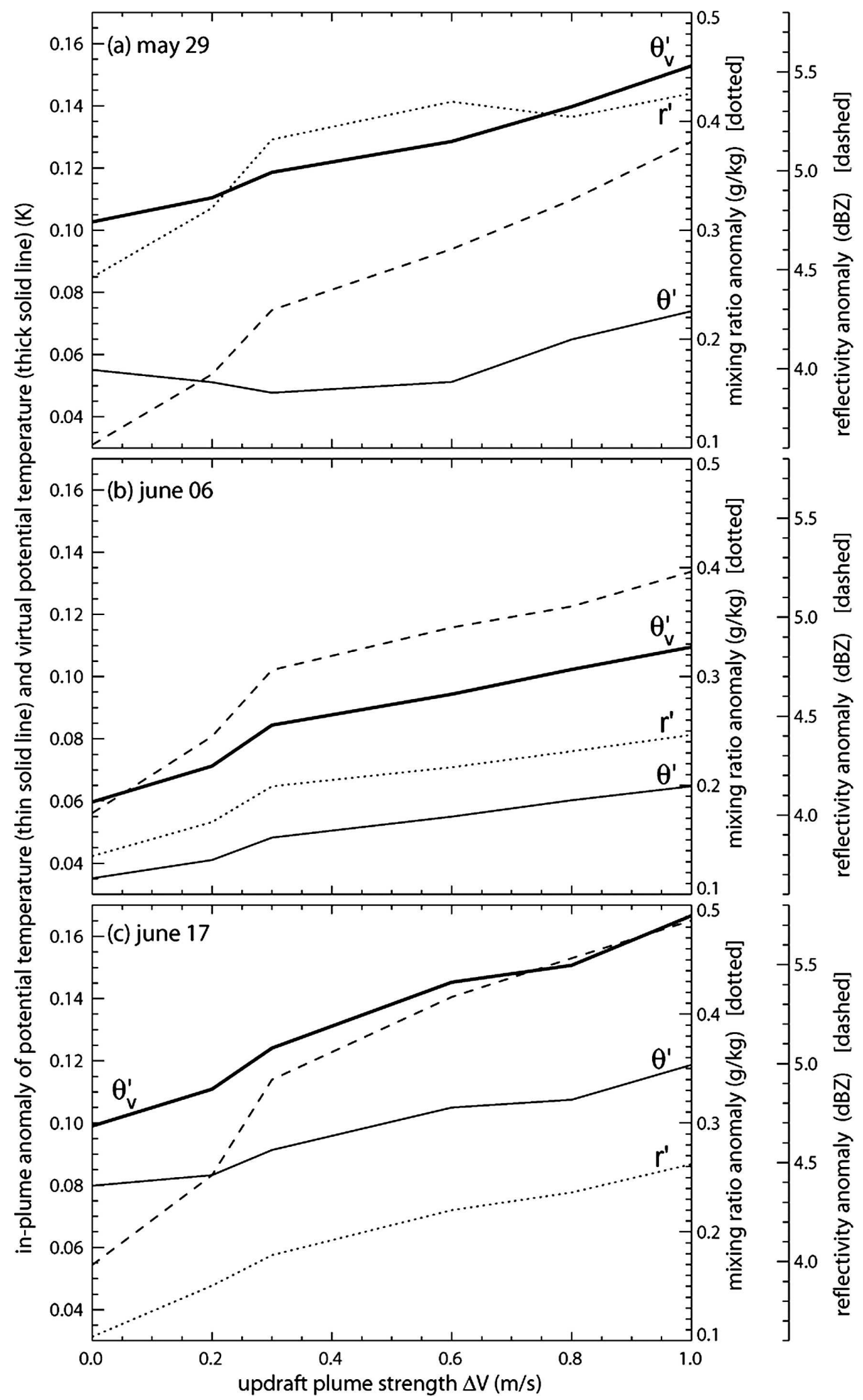

FIG. 12. As in Fig. 7, but for the anomalies in updraft plumes. Also, radar reflectivity anomalies are shown (dashed lines); here reflectivity is averaged over 14 range gates at close range. 

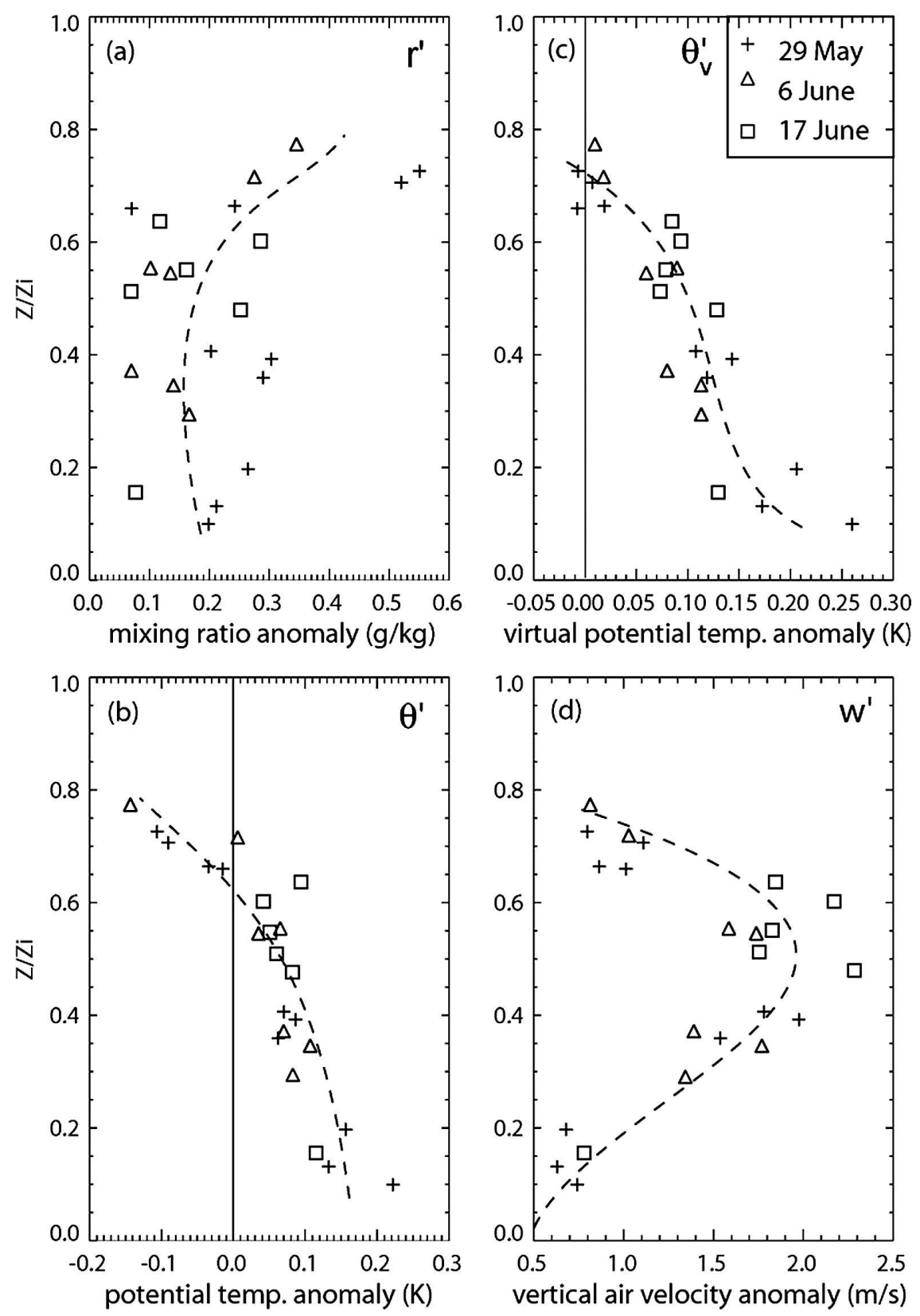

FIG. 13. As in Fig. 8, but for updraft plumes. The updraft plume strength $\Delta V$ is $0.0 \mathrm{~m} \mathrm{~s}^{-1}$.

plicitly been assumed in previous work, but has not been shown.

It should be emphasized that the results are based on averages over relatively long flight legs. Locally the relationship may be poor. This is interpreted as being because of a time lag between dynamic forcing, vertical motion, and insect response. For instance, incipient ascents may be devoid of high insect concentrations, and the upper CBL may contain insect "anvils" without rising motion. This apparent time lag becomes more important when the dynamic forcing in the $\mathrm{CBL}$ is more transient. The reasonable correlations described here suggest that while echo plumes may result from a temporal integral of updrafts, the integration time scale appears reasonably short, that is, insect densities adjust relatively quickly to the distribution of thermals.

\section{Conclusions}

The properties of radar-inferred coherent eddies within the optically clear, weakly sheared continental convective boundary layer have been investigated using 
a conditional sampling technique. The analysis was based on aircraft and airborne millimeter-wave radar observations on three fair-weather days in late spring in the central Great Plains of the United States. Two radar-inferred variables were used to describe the spatial organization within the CBL: reflectivity and vertical air motion. Both variables were sampled conditionally, and the thermodynamic properties of plumes of higher reflectivity ("echo plumes") or higher vertical air velocity ("updraft plumes") were assessed by means of in situ aircraft measurements. The following are the key conclusions:

- The CBL depth and its local variations are captured well by the radar reflectivity profiles.

- The distribution of widths of both echo plumes and updraft plumes shows an exponential decay, peaking at or close to the minimum size of $120 \mathrm{~m}$. Updraft plumes are generally narrower and more numerous than echo plumes.

- The thermodynamic properties of updraft plumes are quite similar to those of echo plumes. Echo plumes are generally rising and buoyant, and the buoyancy is partly because of excess warmth, and partly because of excess water vapor. Water vapor anomalies are important in the local bulging of the CBL depth above echo plumes. In general, the updraft strength and buoyancy of echo plumes increases with the relative echo strength. The magnitude of the buoyancy agrees with that of the associated updraft.

- Thus, echo plumes and updraft plumes generally correspond to coherent buoyancy-driven eddies responsible for much of the vertical energy transfer in the CBL. The in-plume buoyancy and vertical velocity profiles are indicative of entrainment in rising plumes.

- The key implication is that spatial patterns of clearair echoes within the CBL (as commonly captured in low-elevation scans of operational ground-based radars) depict the distribution of rising convective plumes.

Acknowledgments. This research was supported by the National Science Foundation Grant ATMS0129374. Dave Leon processed the WCR radial velocities. Sam Haimov was responsible for the WCR data collection. The HRDL-based $z_{i}$ estimates were provided by Ken Craig.

\section{REFERENCES}

Angevine, W. M., S. K. Avery, and G. L. Kok, 1993: Virtual heat flux measurements from a boundary-layer profiler-RASS compared to aircraft measurements. J. Appl. Meteor., 32, 1901-1907.
Berg, L. K., 2002: A simple parameterization coupling the convective daytime boundary layer and fair-weather cumuli. Ph.D. dissertation, University of British Columbia, 157 pp.

Cohn, S. A., and W. M. Angevine, 2000: Boundary layer height and entrainment zone thickness measured by lidars and windprofiling radars. J. Appl. Meteor., 39, 1233-1247.

Cooper, D. I., W. E. Eichinger, S. Barr, W. Cottingame, M. V. Hynes, C. F. Keller, C. F. Lebeda, and D. A. Poling, 1996: High-resolution properties of the equatorial Pacific marine atmospheric boundary layer from lidar and radiosonde observations. J. Atmos. Sci., 53, 2054-2075.

Crum, T. D., and R. B. Stull, 1987: Field measurements of the amount of surface layer air versus height in the entrainment zone. J. Atmos. Sci., 44, 2743-2753.

— — - and E. W. Eloranta, 1987: Coincident lidar and aircraft observations of entrainment into thermals and mixed layers. J. Climate Appl. Meteor., 26, 774-788.

Davis, K. J., N. Gamage, C. R. Hagelberg, C. Kiemle, D. H. Lenschow, and P. P. Sullivan, 2000: An objective method for deriving atmospheric structure from airborne lidar observations. J. Atmos. Oceanic Technol., 17, 1455-1468.

Doswell, C. A., III, and P. M. Markowski, 2004: Is buoyancy a relative quantity? Mon. Wea. Rev., 132, 853-863.

Doviak, R. J., and M. Berger, 1980: Turbulence and waves in the optically clear planetary boundary layer resolved by dualDoppler radars. Radio Sci., 15, 297-317.

Edwards, B., 2004: Evaluating the convective atmospheric boundary layer by using surface station data. UCAR SOARS Program Summer Report, 407 pp. [Available from University Corporation for Atmospheric Research, P.O. Box 3000, Boulder, CO 80307.]

Ferrare, R. A., J. L. Schols, E. W. Eloranta, and R. Coulter, 1991: Lidar observations of banded convection during BLX83. $J$. Appl. Meteor., 30, 312-326.

Geerts, B., and Q. Miao, 2005a: The use of millimeter Doppler radar echoes to estimate vertical air velocities in the fairweather convective boundary layer. J. Atmos. Oceanic Technol., 22, 225-246.

—, and — , 2005b: A simple numerical model of the flight behavior of small insects in the atmospheric convective boundary layer. Environ. Entomol., 34, 353-360.

Gossard, E. E., 1990: Radar research on the atmospheric boundary layer. Radar in Meteorology, D. Atlas, Ed., Amer. Meteor. Soc., 477-533.

Greenhut, G. K., and S. J. S. Khalsa, 1982: Updraft and downdraft events in the atmospheric boundary layer over the equatorial Pacific Ocean. J. Atmos. Sci., 39, 1803-1818.

Hardy, K. R., and H. Ottersten, 1969: Radar investigations of convective patterns in the clear atmosphere. J. Atmos. Sci., 26, 666-672.

Kaimal, J. C., J. C. Wyngaard, D. A. Haugen, O. R. Cote, Y. Izumi, S. J. Caughey, and C. J. Readings, 1976: Turbulence structure in the convective boundary layer. J. Atmos. Sci., 33, 2152-2169.

Khalsa, S. J. S., and G. K. Greenhut, 1985: Conditional sampling of updrafts and downdrafts in the marine atmospheric boundary layer. J. Atmos. Sci., 42, 2550-2562.

Kiemle, C., M. Kästner, and C. Ehret, 1995: The convective boundary layer structure from lidar and radiosonde measurements during the EFEDA'91 campaign. J. Atmos. Oceanic Technol., 12, 771-782.

Konrad, T. G., 1970: The dynamics of the convective process in clear air as seen by radar. J. Atmos. Sci., 27, 1138-1147. 
LeMone, M. A., 1973: The structure and dynamics of horizontal roll vortices in the planetary boundary layer. J. Atmos. Sci., 30, 1077-1091.

— search, early results, and opportunities in the Walnut River watershed in southeast Kansas: CASES and ABLE. Bull. Amer. Meteor. Soc., 81, 757-780.

—, R. L. Grossman, F. Chen, K. Ikeda, and D. Yates, 2003: Choosing the averaging interval for comparison of observed and modeled fluxes along aircraft transects over a heterogeneous surface. J. Hydrometeor., 4, 179-195.

Lenschow, D. H., 1972: The measurement of air velocity and temperature using the NCAR Buffalo aircraft measuring system. NCAR Tech. Note NCAR-TN, EDD-75, 39 pp.

— vective boundary layer. Bound.-Layer Meteor., 19, 509-532.

_ , J. C. Wyngaard, and W. T. Pennell, 1980: Mean field and second moment budgets in a baroclinic, convective boundary layer. J. Atmos. Sci., 37, 1313-1326.

Leon, D., G. Vali, and M. Lothon, 2006: Dual-Doppler analysis in a single plane from an airborne platform. J. Atmos. Oceanic Technol., 23, 3-22.

Lohou, F., B. Campistron, A. Druilhet, P. Foster, and J. P. Pages, 1998a: Turbulence and coherent organizations in the atmospheric boundary layer: A radar-aircraft experimental approach. Bound.-Layer Meteor., 86, 147-179.

_ _ A. Druilhet, and B. Campistron, 1998b: Spatial and temporal characteristics of horizontal rolls and cells in the atmospheric boundary layer based on radar and in situ observations. Bound.-Layer Meteor., 89, 407-444.

Manton, M. J., 1977: On the structure of convection. Bound.Layer Meteor., 12, 491-503.

Marsik, F. J., K. W. Fischer, T. D. McDonald, and P. J. Samson, 1995: Comparison of methods for estimating mixing height used during the 1992 Atlanta field intensive. J. Appl. Meteor., 34, 1802-1814.

Mayor, S. D., G. J. Tripoli, and E. W. Eloranta, 2003: Evaluating large-eddy simulations using volume imaging lidar data. Mon. Wea. Rev., 131, 1428-1452.

Melling, H., and R. List, 1980: Characteristics of vertical velocity fluctuations in a convective urban boundary layer. J. Appl. Meteor., 19, 1184-1195.

Nicholls, S., and M. A. LeMone, 1980: The fair weather boundary layer in GATE: The relationship of subcloud fluxes and structure to the distribution and enhancement of cumulus clouds. J. Atmos. Sci., 37, 2051-2067.
Pazmany, A., R. McIntosh, R. Kelly, and G. Vali, 1994: An airborne $95 \mathrm{GHz}$ dual-polarized radar for cloud studies. IEEE Trans. Geosci. Remote Sens., 32, 731-739.

Readings, C. J., E. Golton, and K. A. Browning, 1973: Fine-scale structure and mixing within an inversion. Bound.-Layer Meteor., 4, 275-287.

Reinking, R. F., R. J. Doviak, and R. O. Gilmer, 1981: Clear-air roll vortices and turbulent motions as detected with an airborne gust probe and dual-Doppler radar. J. Appl. Meteor., 20, 678-685.

Russell, R. W., and J. W. Wilson, 1997: Radar-observed "fine lines" in the optically clear boundary layer: Reflectivity contributions from aerial plankton and its predators. Bound. Layer Meteor., 82, 235-262.

Schumann, U., and C. Moeng, 1991: Plume fluxes in clear and cloudy convective boundary layers. J. Atmos. Sci., 48, 17461757.

Scorer, R. S., 1957: Experiments on convection of isolated masses of buoyant fluid. J. Fluid Mech., 2, 583-594.

Stull, R. B., 1988: An Introduction to Boundary Layer Meteorology. Kluwer Academic, 666 pp.

Wang, S., and B. Stevens, 2000: Top-hat representation of turbulence statistics in cloud-topped boundary layers: A large eddy simulation study. J. Atmos. Sci., 57, 423-441.

Weckwerth, T., and Coauthors, 2004: An overview of the International $\mathrm{H}_{2} \mathrm{O}$ Project (IHOP_2002) and some preliminary highlights. Bull. Amer. Meteor. Soc., 85, 253-277.

White, A. B., C. J. Senff, and R. M. Banta, 1999: A comparison of mixing depths observed by ground-based wind profilers and an airborne lidar. J. Atmos. Oceanic Technol., 16, 584-590.

Wilson, J. W., G. B. Foote, N. A. Crook, J. C. Fankhauser, C. G. Wade, J. D. Tuttle, C. K. Mueller, and S. K. Krueger, 1992: The role of boundary-layer convergence zones and horizontal rolls in the initiation of thunderstorms: A case study. Mon. Wea. Rev., 120, 1785-1815.

_, T. M. Weckwerth, J. Vivekanandan, R. M. Wakimoto, and R. W. Russell, 1994: Boundary-layer clear-air radar echoes: Origin of echoes and accuracy of derived winds. J. Atmos. Oceanic Technol., 11, 1184-1206.

Xu, M., and T. Gal-Chen, 1993: A study of the convective boundary-layer dynamics using single Doppler radar measurements. J. Atmos. Sci., 50, 3641-3662.

Young, G. S., 1988: Turbulence structure of the convective boundary layer. Part II: Phoenix 78 aircraft observations of thermals and their environment. J. Atmos. Sci., 45, 727-735. 